\title{
Vivências em tempos de pandemia dos principais atores do sistema escolar brasileiro: docentes, discentes e familiares
}

\author{
Experiences in times of pandemic of the main actors of the brazilian school system: \\ teachers, students and parentes
}

Expériences en temps de pandémie des principaux acteurs du système scolaire brésilien: enseignants, élèves et parentes

Nair Cristina da Silva Tuboiti ${ }^{1}$ Universidade Católica de Brasília

Candy E. Marques Laurendon² Universidade Federal de Pernambuco

Lêda Gonçalves de Freitas ${ }^{3}$ Universidade Católica de Brasília

Line Numa-Bocage ${ }^{4}$ CY Cergy Paris Université (CYU)

Resumo: Com o objetivo de observar e discutir como ocorrem as relações de ensinoaprendizagem entre docentes, discentes, familiares e escola no contexto pandêmico, analisamos seis entrevistas semiestruturadas (com pares de estudantes, educadoras e mães), extraídas de uma pesquisa sobre vivências de crianças e jovens, que, de acordo com a teoria interpretativa de Geertz (2008) e dos núcleos de significações de Aguiar e Ozella (2006), revelaram sentimentos profundos de isolamento social por parte dos discentes, mas também momentos felizes entre os familiares. As mães tentam pensar novas estratégias para suprir a falta de aulas e acompanhamento escolar em casa. Os docentes sinalizam as dificuldades de elaboração de estratégias de ensino remoto aliadas às dificuldades relacionadas ao contexto doméstico e pessoal.

Palavras-chave: Pandemia. Ensino-aprendizagem. Relações escolares e familiares. Afetos.

\begin{abstract}
In order to observe and discuss how teaching-learning relationships are made between teachers, students, family members and school in the pandemic context, six semi-structured interviews (with pairs of students, teachers, and mothers) from research on children's and youth's

\footnotetext{
1 Pós-doutoranda pela Universidade Católica de Brasília. Estudante na Universidade Católica de Brasília. E-mail: ncstuboiti@gmail.com. Lattes: http://lattes.cnpq.br/0530351354120033.ORCID: https://orcid.org/0000-0002-5641-8057. 2 Pós-doutorado pela Universidade Federal de Pernambuco. Professora Adjunta do Departamento de Psicologia e Orientação Educacionais da UFPE - Programa de Pós-Graduação em Psicologia Cognitiva. E-mail: nacyda@gmail.com. Lattes: http://lattes.cnpq.br/6050113733387823. ORCID: https://orcid.org/0000-0002-5670-2824.

${ }_{3}^{3}$ Pós-doutorado pelo Conservatoire National des Arts et Métiers (CNAM-Paris/França). Professora Titular do Programa de Mestrado e Doutorado da Universidade Católica de Brasília. E-mail: ledagfr@gmail.com. Lattes: http://lattes.cnpq.br/8076487547964658. ORCID: https://orcid.org/OOOO-0002-1288-7134.

${ }^{4}$ Doutorado pela Université Paris 5. Professeure des Universités, HDR à l'université de Cergy-Pontoise. Chercheure à titre principal au laboratoire BONHEURS.E-mail:ine.numa-bocage@u-cergy.fr e line.numa.bocage@gmail.com. Curriculum: http://laboratoire-bonheurs.fr/spip.php?article30. ORCID: https://orcid.org/0000-0001-7307-2281.
} 
experiences revealing, according to Geertz's (2008) interpretive theory and Aguiar and Ozella's (2006) meaning cores, their strong feelings of social isolation, as well as family happiness. Mothers try to imagine new strategies to compensate for the absence of classes and school frequency. Teachers note the difficulties in developing distance learning strategies combined with the difficulties of this context.

Keywords: Pandemic. Teaching-learning. School and family relations. Affections.

Résumé: Afin d'observer et de discuter la manière dont les relations d'enseignementapprentissage se font entre les enseignants, les élèves, la famille et l'école dans le contexte pandémique, on analyse six entretiens semi-structurés (avec des paires d'élèves, des enseignantes et des mères) extraits d'une recherche sur les expériences des enfants et des jeunes révélant, selon la théorie interprétative de Geertz (2008) et les noyaux de significations d'Aguiar et Ozella (2006), ses forts sentiments d'isolement social, ainsi que du bonheur en famille. Les mères essaient d'imaginer des nouvelles stratégies pour compenser l'absence de cours et de fréquence scolaire. Les enseignants notent les difficultés à élaborer des stratégies d'enseignement à distance alliées aux difficultés de ce contexte.

Mots clés: Pandémie. L'enseignement et l'apprentissage. Relations entre l'école et la famille. Affections.

Recebido em: 15 de julho de 2021 Aceito em: 09 de setembro de 2021

\section{Introdução}

O contex to de crise sanitária mundial devido à pandemia da Covid-19 provocou transformações nas rotinas de vida dos brasileiros, a partir de março de 2020. Com a adoção do isolamento social determinado pelo governo de grande parte dos municípios do país, os deslocamentos foram drasticamente reduzidos para milhões de pessoas e a regra estabelecida para todos foi ficar em casa. Este contexto acarretou diversas transformações em diferentes setores da sociedade. No Brasil, os estabelecimentos comerciais de produtos não essenciais foram fechados; e no que tange ao setor educacional, as aulas presenciais foram suspensas em todas as modalidades de ensino.

O contexto da pandemia provocou, portanto, transformações e mudanças nas relações entre os diferentes atores do sistema escolar (docentes, discentes, familiares). Para alguns estados no Brasil, em função das decisões dos diferentes governos estaduais, iniciou-se um processo gradual de volta às aulas na modalidade virtual on-line, tal como procedido no Distrito Federal (DF), a partir de junho de 2020. A mudança da rotina diária das pessoas levou a uma série de dificuldades e sofrimentos psíquicos, seja o luto pelos planos perdidos ou o choque pela restrição da liberdade.

De modo geral, as pesquisas revelam que "os indivíduos submetidos ao isolamento social estão mais suscetíveis a apresentar transtornos de saúde mental, devido à privação e contenção 
social, surgindo sintomas de sofrimento psíquico, em especial, relacionado ao estresse, ansiedade e depressão" (PEREIRA, et al., 2020, p. 1). Da mesma forma, no setor educacional, os diferentes atores do sistema escolar, em especial os docentes e discentes, estão apresentando "dificuldades, tais como a ansiedade, o estresse emocional, a privação de sono, o distanciamento social e o isolamento social” (PEREIRA, et al., 2020, p. 1).

Poucas pesquisas têm colocado seu foco nas vivências dos discentes durante a pandemia. Por parte destes, obrigados ao isolamento social, surgem sentimentos de saudade dos colegas, da escola e dos docentes, e que, em consequência, resultam em dificuldades no processo de aprendizagem. Dificuldades, inicialmente, de acesso às informações para uma parte dos discentes, acentuaram as desigualdades sociais, ao revelar a falta de acesso às novas tecnologias e à internet pela classe social popular, portanto, discentes das escolas públicas brasileiras.

Diante deste quadro, como profissionais da educação, nos questionamos: Como os tempos de pandemia têm contribuído para transformar as relações entre os diferentes atores do sistema escolar? O objetivo desse artigo é, portanto, observar e discutir como ocorrem as relações de ensino-aprendizagem de forma remota, entre docentes, discentes e familiares, entre sistema familiar e sistema escolar, focando principalmente nas vivências e aprendizagens dos estudantes, para propor reflexões para um cenário pós-pandemia, no caso de uma possível retomada das aulas presenciais e a prevenção de dificuldades no processo de ensino-aprendizagem.

Esta discussão parte da análise de seis entrevistas semiestruturadas, a fim de identificar os diversos sentimentos dos principais atores do sistema escolar (duas docentes, dois estudantes de ensino médio e duas mães), entrevistas extraídas de uma pesquisa internacional mais ampla que trata das vivências de crianças e jovens em tempos de pandemia (Djeuns Covid-19)5. Os dados coletados foram organizados e analisados à luz da teoria interpretativa de Geertz (2008), em busca do significado que emerge da fala do pesquisado e dos núcleos de significações (AGUIAR; OZELLA, 2006), para favorecer uma compreensão das vivências atuais, principalmente dos discentes e outros atores do sistema escolar.

Após breve revisão da literatura sobre as consequências da crise sanitária atual, particularmente na área educacional, apresentamos a metodologia utilizada e os principais resultados da pesquisa em relação aos sentimentos e rotinas diárias de estudo como possíveis indícios para prevenção das dificuldades de retomada das aulas presenciais.

\footnotetext{
5 Pesquisa realizada, com crianças e jovens no período do confinamento, por CY-Cergy Paris Université, representada pelo laboratório BONHEURS, associada à Art Déco e às Universidades do Brasil (UCB e UFPE familiares emergentes), de Sherbrooke (membro da AUF) e de Burkina Faso (compartilhado com América e África). A associação Art Déco recebeu e tratou os dados provenientes das entrevistas com o objetivo de prevenir as dificuldades de reinserção escolar após o confinamento. https://www.auf.org/nos-actions/toutes-nosactions/apprentissages-des-jeunes-et-enfants-malgre-le-confinement-et-contre-le-covid-19/.
} 
São assim discutidos os sentimentos profundos de isolamento social expressos pelos discentes, e também momentos felizes compartilhados com a família. As estratégias identificadas remetem, do lado das mães, à tentativa de suprir a falta de aulas remotas e acompanhamento escolar em casa, e do lado dos docentes, à elaboração de estratégias de ensino para motivar os discentes e encorajar o acompanhamento escolar por parte das famílias.

\section{As vivências dos principais atores nos estudos}

Após a paralisação das aulas devido à pandemia da Covid-19, a literatura recente destaca inicialmente "as dificuldades de estrutura e oferta de serviços destinados à realização de atividades educativas remotas, tanto para docentes e para discentes". E estas “dificuldades apresentadas no ensino remoto são de certa forma catalisadoras do estresse emocional” (CIPRIANO; ALMEIDA, 2020, p. 3-4), tanto para os docentes quanto para os discentes. Entre as consequências da crise sanitária sobre a saúde mental das pessoas, o estudo de Pereira et al. (2020, p. 1) destaca as "dificuldades, tais como a ansiedade, o estresse emocional, a privação de sono, o distanciamento social e o isolamento social" dos discentes, docentes e familiares.

No que tange às rotinas de estudo de estudantes, Santos e Mendonça revelam as dificuldades de cinco discentes (de 9 a 11 anos)

em acompanhar as aulas remotas no que se refere à falta de relacionamento com os colegas pelas conversas e brincadeiras, em como é abordado o conteúdo sem a presença física do professor, assim como, a indisposição para assistir as aulas mesmo com o incentivo dos familiares. (SANTOS; MENDONÇA, 2020, p. 1).

Assim, das cinco crianças entrevistadas, poucas expressam uma aceitação positiva da nova metodologia de ensino; a maioria avalia negativamente, apontando para as dificuldades de acesso à internet (queda da conexão) e dificuldades para esclarecer dúvidas em razão do excesso de perguntas. Também se destaca a falta de motivação pessoal e de engajamento dos discentes nas aulas remotas:

A maioria não se sente motivada, utilizando as expressões: é chato ficar só ouvindo a educadora falar e a gente não poder falar a resposta pessoalmente [...] não me sinto motivada, pois sinto muita falta do contato físico com todos (SANTOS; MENDONÇA, 2020, p. 124).

Por outro lado, para os docentes, o contexto de crise sanitária atual leva a pensar novas formas de ensinar e aprender, "considerando o que se tem em casa, o envolvimento da família e a vida de distanciamento social” (HONORATO; MARCELINO, 2020, p. 212), focando na aprendizagem dos estudantes, realizando muitas vezes uma "transposição didática emergencial da educação presencial tradicional para as redes” (MARTINS; ALMEIDA, 2020, p. 7). Ao instaurar uma modalidade de ensino remoto, os docentes sofrem de sobrecarga de trabalho, pois 
este entrou de vez no universo doméstico dos docentes, transformando as suas práticas de gestão de tempo e espaço doméstico (HONORATO; MARCELINO, 2020).

De modo geral, as pesquisas atuais sobre o ensino remoto e as relações escola/família revelam que o contexto de pandemia provocou uma maior aproximação entre as famílias e os docentes e seus(suas) filhos(as) (BAHIA, 2020; SENTINELI; INSFRAN, 2020). Para beneficiar o processo de ensino-aprendizagem dos discentes, surge a necessidade, para as famílias, de construir "espaços de aprendizagem arejados e iluminados, dentro das residências, bem como a composição de um pacto social entre familiares e professor, em que pese a escolha do melhor horário para realização dessas atividades remotas” (ALVES, 2020, p. 35).

Para a implantação e permanência das modalidades de ensino remoto de modo eficiente, o diálogo entre a escola e as famílias revela-se essencial. Neste sentido, o meio de comunicação privilegiado entre o sistema escolar e as famílias tem sido o WhatsApp, usado para passar as atividades remotas e fazer o acompanhamento da realização destas.

E por parte das famílias, quanto à mãe no papel de responsável por acompanhar a modalidade remota de atividades em casa para seus filhos, vejamos o que consideram os autores:

\begin{abstract}
As mães avaliaram o ensino remoto de forma positiva, no sentido de manter seus filhos protegidos e isolados nesse momento em que a saúde está em risco. [...] Elas, no geral, entendem esse formato como uma reinvenção das formas de ensinar e aprender para enfrentarmos esses tempos. Destacaram que as aulas ao vivo amenizam um pouco a falta de interação social, aspecto negativo desse método educativo. (SENTINELI; INSFRAN, 2020, p. 132).
\end{abstract}

$\mathrm{O}$ ambiente escolar constituindo um meio de intensas vivências afetivo-sociais essenciais às aprendizagens e consequente desenvolvimento das crianças, no contexto do enfrentamento da Covid-19, faz surgir algumas perguntas: Como as crianças e jovens têm vivenciado o isolamento social? Quais sentimentos e afetos surgiram neste período? Qual é a rotina de estudos que crianças e jovens têm instaurado durante o "confinamento" de 2020 ?

\title{
Metodologia
}

Para tentar responder a estas perguntas e ao objetivo do presente artigo, optamos por realizar entrevistas semiestruturadas 6 e on-line, uma vez que estávamos em pleno isolamento social. A escolha dos entrevistados teve como universo seis escolas públicas do Distrito Federal (DF), buscando as áreas de maior vulnerabilidade em função da complexidade desse momento de ensino remoto.

\footnotetext{
${ }^{6}$ Os temas propostos no roteiro da entrevista relacionam-se com sentimentos provenientes do isolamento social em tempos de Covid-19, atividades do cotidiano, relações familiares, escolares e outras, as dificuldades enfrentadas, aprendizagens desse período, entre outros aspectos apontados pelos participantes.
} 
As entrevistas audiogravadas foram realizadas via chamada de áudio no WhatsApp. Para o objetivo deste artigo, a partir de uma pesquisa internacional maior, selecionamos seis entrevistas, entre os 35 entrevistados no Brasil, sendo dois estudantes, duas educadoras e duas mães ${ }^{7}$, para representar os diferentes segmentos do sistema escolar e familiar diretamente envolvidos com o processo de ensino-aprendizagem.

Os dados coletados foram organizados e analisados à luz da teoria interpretativa de Geertz (2008), em busca de compreender o significado expresso pelos sujeitos pesquisados, e dos núcleos de significações (AGUIAR; OZELLA, 2006), em temáticas que traduziram os sentidos e aspectos subjetivos expressos nas entrevistas. Após a transcrição das entrevistas, em uma primeira leitura evidenciamos o que foi significado pelos entrevistados, palavras e/ou expressões. Em leituras posteriores, fomos direcionados para formas de ser e o vivenciado pelas pessoas, aglutinando tudo pela similaridade, pela complementaridade ou pela contraposição.

Dessa maneira, o processo de análise teve como enfoque os objetivos, ao considerar o significado que emerge da fala dos entrevistados, articulada ao olhar interpretativo do sujeito em seu contex to sociocultural, buscando apreender os sentidos e a subjetividade dos entrevistados, tendo em vista os núcleos de significação, em um diálogo analítico com o corpus teórico (TUBOITI, 2018; AGUIAR; OZELLA, 2006).

\section{Os relatos dos principais atores escolares entrevistados}

O processo de análise dos dados permitiu identificar quatro núcleos de significação: tempos e rotinas em contexto de pandemia; ensino-aprendizagem e novas configurações; contradições de uma nova maneira de estar em aula; afetos implicados nesse processo. Antes de tudo, é importante situarmos quem são as pessoas participantes da pesquisa:

- Uma estudante (Ane, 14 anos, $9^{\circ}$ ano) e um estudante (Thomas, 14 anos, $9^{\circ}$ ano), de classe média, moram em cidades da periferia do DF e estudam em escolas públicas;

- Duas educadoras (Samara, 49 anos, e Riana, 40 anos), também de escolas públicas, sendo uma delas atuante em sala de aula com discentes dos anos finais e a outra atuando com anos iniciais do ensino fundamental, e vivem em regiões administrativas de classe média do DF.

- Duas mães (Dara, 49 anos, e Elaine, 40 anos), ambas de classe média, moram em cidades da periferia do DF, trabalham na área da educação, e seus filhos estudam em escola pública.

Tempos e rotinas em contexto de pandemia - Para nos situarmos quanto aos conceitos tempos/rotinas, partimos de uma análise dos tempos gregos. O tempo cronológico (khrónos) nos direciona para uma perspectiva de uniformidade, padrão, rotina; o tempo da oportunidade (kairós),

\footnotetext{
7 Esclarecemos ainda que para garantir a confidencialidade e o sigilo da identidade dos participantes utilizamos nomes fictícios.
} 
é marcado pela decisão do que fazer ou não; e o da experiência (aión), estabelecido com base no desejo intenso, subjetivo e envolto pela afetividade, é dinâmico (KOHAN, 2015, 2016). De outro lado, é importante tomar essas três possibilidades e trazer luz para o sentido da rotina, de modo que seja qualitativa e não caia em ações padronizadas pelo tempo khrónos, simplesmente pautada no hábito de fazer algo sempre do mesmo modo, mecanicamente. É na articulação das três possibilidades de tempo expressas que alimentamos o sentido de rotina e pautamos nossas análises.

Esse momento vivido pode ser provocador de ações ou não, ele pode direcionar para o uso do tempo/rotina com qualidade ou apenas ficar focado em escapes; observamos como, nos três diferentes lugares, os entrevistados deste estudo o utilizam, e como criam alternativas.

O discurso dos estudantes revela uma preocupação com o momento de isolamento, destacando a dificuldade de organizar esse tempo que se abre:

\begin{abstract}
A gente fica muito tempo em casa, muita energia acumulada [...] Tem dias que dá para conviver, tipo é bom, dá pra estudar, dá para fazer as coisas. Mas tem dias que também não dá para fazer nada, que a gente acorda com desânimo... [...] tenho dificuldade em formular horários, não tenho horário fixo para quase nada. (Ane, estudante).

[...] Algo um pouco difícil para mim, porque eu tenho uma dificuldade em formular horários [...] eu não tenho horários fixos para quase nada, mas eu procuro fazer tudo possivel [...] não preciso sair de casa, mas é um pouco dificil para mim, sou um pouco desorganizado nesse quesito de horário. (Thomas, estudante).
\end{abstract}

Ter tempo não significa saber administrá-lo a ponto de ter uma rotina, principalmente quando se vive uma situação de isolamento social determinado, que envolve muitas complexidades, e que atravessa a vida de outros. De outra mirada, esse conflito com o tempo/rotina expressa-se de forma semelhante nas falas das educadoras e das mães, revelando o impacto do isolamento social: Tem sido muito difícil, sempre sou muito social (Samara), Chocada [...] tenho que ficar trancada [...] então se tornou muito cansativo [...] articular as tarefas domésticas, pessoais, trabalho... me organizei e passei a atendê-los somente à tarde (Riana).

Algumas falas destacam a dificuldade e o cansaço para articular/coordenar as diferentes tarefas: Tem sido difícil acompanhar os estudos do meu filho pois no mesmo horário que ele está nas aulas online eu estou em home office [...] conciliar essas dinâmicas sem sair do lugar tem sido um desafio (Elaine); tenho sentido o peso do teletrabalho, a casa da gente virou escola (Dara). Ao administrar o tempo e o que se tem para fazer, e ainda em um contexto de pandemia, o conflito se instaura em razão da energia e atividades acumuladas, não sabendo como conciliar diferentes dinâmicas sem poder sair de casa, gerando uma paralisia permeada pelo estresse.

Diante desse desafio e/ou caos, busca-se alternativas e ações para ressignificar a situação. Algumas estratégias citadas pelos entrevistados remetem à atividade física, ao autoconhecimento, à meditação, atitudes que mexem com as questões subjetivas para fortalecer e enfrentar melhor 
o cotidiano. Isso é revelado nas falas de Thomas e Ane, respectivamente: Tentar fazer atividades físicas aeróbicas, assistir filmes nessa quarentena está sendo muito bom, jogar videogame; Um tempo de repensar muitas coisas que devo fazer para aproveitar a vida, como ir ao parque, entre outras coisas.

Da mesma forma, as educadoras e as mães buscam alternativas para as problemáticas desse momento, como relatam: A gente teve que se estabelecer rotinas novamente [...] articular as tarefas domésticas, pessoais, trabalho [...] ressignificar o tempo com a familiares (Riana); $A$ atividade física tem me tirado de vários sufocos mentais [...] comecei a fazer coisas que não fazia como cuidar da casa, pintar a casa [...] (Samara); Estou procurando fazer meditação, é preciso cuidar do nosso emocional (Elaine). As atitudes reveladas nas diferentes narrativas nos direcionam a pensar o quanto é necessário o tempo do distanciamento, da pausa, para colocar ordem no caos.

Além das estratégias de enfrentamento da pandemia, diante do isolamento social, os sujeitos ressignificam esses momentos para salientar alguns aspectos positivos, tal como o estudante Thomas destaca quanto à convivência familiar: Está sendo muito legal conviver, ficar com meu pai e com minha mãe o dia todo. De outro lado, Ana faz uma autorreflexão:

Estou começando a tirar mais tempo para mim [...] coisas que eu deixei de fazer, agora estou fazendo de novo. Eu estou descobrindo muita coisa que eu não sabia sobre mim, […] quando se está em isolamento você está muito com você mesma, então acaba se descobrindo.

As reações foram diversas até conquistar esse novo lugar, e os adultos também viveram esse lado, como afirma Dara: No começo a gente não sabe muito bem em que passo está a caminhada, né? Depois a gente vai melhorando. Essa melhora teve, em algumas atividades diferenciadas das tarefas "obrigatórias", um distanciamento necessário para seguir em frente e/ou nutrir-se na proximidade com os familiares: Temos tido boas conversas com os familiares (Riana); Estamos mais próximos (Elaine).

Transformar o tempo presente para além do khrónos implica abrir espaço para pensar, preparar e concretizar um lugar para o tempo da experiência e da oportunidade, envolve olhar o passado para ressignificá-lo, significa ser capaz de assegurar a devida articulação entre presente, passado e futuro. Nessas bases, os impactos do isolamento incidiram sobre as vivências pessoais, familiares e escolares; por um determinado tempo todos foram "obrigados" a reestruturar esses momentos dentro de seus lares, para então (des)ensinar e seguir.

Ensino-aprendizagem: novas configurações - Visto que somos seres sociais e produtores de cultura na nossa gênese, entende-se que ser privado dessas relações é diminuir as possibilidades de crescimento. Tanto os estudantes quanto os adultos, na pessoa das educadoras e/ou mães, foram profundamente tocados pela falta do contato, como é expresso 
nas seguintes falas: Falta contato com os docentes (Ane); Não tenho tido contato com meus docentes (Thomas). E os relatos quanto a isso prosseguem:

Difícil atingir todos os meus discentes [...] não estão ali presentes, não tenho aquele feeling, não tem o sentimento, a sensação que a gente tem no presencial, um olhar do aluno que diz tudo, as conversas com eles sobre as dificuldades que enfrentam ... só de não estar presente e não sentir, não ter aquele sentimento de estar junto, tentar fazer o melhor, isso é muito difícil porque atrás de uma tela, a gente não tem noção de nada. (Samara, educadora).

Essa experiência tem sido difícil, mesmo com todas as mídias a gente perdeu o contato. O contato físico, a presença, a troca de experiência é muito diferente do virtual. (Dara).

Como aprender é um fenômeno social, ou seja, aprendemos na interação com nossos pares e/ou docentes, a falta do contato e/ou do ensino presencial exigiu novas configurações. Afinal, no início do isolamento social, longe do contexto escolar, e especificamente, sem caminhos pensados para ressignificar a lógica escolar presencial, a sensação foi de ficar no limbo, direcionando para alguns arranjos. Assim, os entrevistados, a partir das especificidades de seus lugares no processo de ensino-aprendizagem, buscaram estratégias para dar conta dessa nova dinâmica, mesmo sem aulas inicialmente.

Enquanto isso, os adolescentes tentavam estudar, como se expressa a seguir: Eu todo dia tento estudar um pouco, tipo durante um certo tempo, certo horário (Ane); Alguns docentes enviam algum material e meus familiares ficam me lembrando de estudar, ler (Thomas). As educadoras também não se deixaram sucumbir pela distância: Na segunda semana do isolamento eu fui inventando situações com meus discentes (Samara); Eu não parei, eu continuei atendendo os meus meninos pelo WhatsApp [...] enviava mensagens, todos os dias enviava uma atividade (Riana).

De outro lado, mas extremamente necessárias neste processo, as mães também se posicionaram: No início da pandemia nós já estávamos colocando ele para estudar por conta própria, porque a gente percebeu que estava demorando muito retornar às aulas (Dara); No início, eu mesmo fiz algumas tarefas para proporcionar algumas aprendizagens para ele (Elaine).

A titudes autônomas, num tempo em que não se sabia o que fazer, foi um certo tatear no escuro para que nem tudo ficasse perdido. Pois, no contex to do Distrito Federal, foram três meses de espera sem aulas, o que impulsionou muitas famílias a ir em busca de soluções. Contudo, a preocupação com a aprendizagem dos estudantes pressionou o sistema escolar para buscar alternativas, e passado esse período, veio a necessidade de retornar às aulas.

Assim, de uma maneira inesperada e de certa forma sem pensar nas condições das famílias vinculadas ao sistema de ensino público, a escola teve que pensar como chegar nos discentes [...] e o melhor contato foi a internet (Elaine). Optou-se então pelo ensino remoto. Novamente instaura-se o caos na vida de estudantes, docentes e famílias. Em relação ao ensino remoto, Thomas pontua 
que são difíceis as videoaulas, enquanto Ana assim se expressa: Isso estava me deixando tipo isolada no mundo da internet, tipo só mexendo no computador.

E quem ensina também enfrentou dificuldades:

Os discentes têm muitas dificuldades de acesso [ [...] tenho que agir para incluir [...] fico triste em ver que ela (educação remota) exclui [...] tiveram dificuldade de mexer na plataforma [...] tive que fazer tutorial [...] eles estão aprendendo a lidar com essa tecnologia $[\ldots .$.$] difícil atingir todos os meus discentes. (Samara, educadora).$

Por sua vez, Riana aponta outro aspecto: Eu não curto muito essas coisas (tecnológicas) [...] para mim é extremamente cansativo ficar na frente do computador e ficar presa dentro de casa. Da mesma forma, as duas mães entrevistadas revelam visões opostas quanto ao ensinoaprendizagem: Os docentes postam atividades na plataforma (diferentes tipos) [...] O professor fica disponível para tirar dúvidas (Dara); por sua vez, Elaine revela: Eu percebi que a educadora dele tem dificuldades para fazer essa transferência [...] ela teve que se readaptar e aprender coisas novas, aprender a usar a internet.

Além dos aspectos apontados, a educadora Riana apresenta outro fator complexo: $A$ gente acaba vivenciando muitos problemas deles. Trabalhar de forma remota coloca o sistema escolar dentro do cotidiano familiar dos estudantes, traz em si o constatar de problemas relacionados à violência e a valores, e que desencadeiam comportamentos bem diferenciados, apresentando uma condição de vida fragilizada, o que obriga os docentes a repensar suas ações didático-pedagógicas, no sentido de não potencializar essas questões.

A complexidade desse processo nos leva a pensar e agir em vista de uma perspectiva diferenciada, como também ilustra a seguinte fala do estudante Thomas:

\footnotetext{
Mesmo sendo difícil as videoaulas, é algo libertador, é algo muito interessante, porque você não fica preso ao que a escola te determina, entende? Você consegue ver mais pontos de vista diferentes, você consegue pesquisar mais, você consegue analisar, ler mais, na escola a gente não tem tanto essa oportunidade.
}

Nesse sentido, o processo de ensino-aprendizagem olhado pelo viés do trabalho remoto, apesar das dificuldades provocadas, também instaurou oportunidades de aprendizagens, o que é pontuado pelos estudantes Ana e Thomas, apontando a possibilidade de uma certa autonomia pois são desafiados a pesquisar e desvendar o mundo virtual, na perspectiva das aprendizagens escolares.

Da mesma forma, oportunizam-se novas aprendizagens para os adultos:

A gente está aprendendo muito, fomos obrigados a aprender algo novo [...] acredito que a sala de aula nunca mais vai ser a mesma ... muitos vão agregar a sua prática pedagógica [...] eu acho que está todo mundo aprendendo [...] a gente foi forçado a isso (Samara, educadora). 
A educadora Riana assim refere em relação às mudanças produzidas pelo contexto da pandemia: Experiência nova, desafiadora, oportunidade de crescimento, mudança, coragem para mudar, isso é mexer com sua comodidade, tirou todo mundo da zona de conforto, tive que aceitar e encarar essa mudança. E Dara aponta: a gente está crescendo profissionalmente e está crescendo pessoalmente [...] são aprendizagens pessoais e profissionais [...] A gente está se reinventando [...] inventando maneiras.

Contradições da complexidade do aprender a ensinar - Vivenciado a partir da forma remota, tem-se a grande possibilidade de construir novos tempos e aprendizagens para avançar em direção à qualidade da educação. E assim, para além de postar atividades para os discentes, a educadora Riana, mesmo ponderando as dificuldades desse momento ao relatar o quanto é penoso e cansativo ficar na frente do computador, tem no WhatsApp uma alternativa e inventa estratégias envolvendo situações na área da leitura e escrita, interpretação, problemas matemáticos, para isso utilizando-se de pequenos grupos em que tem sentido que o trabalho flui pois no pequeno grupo tem sido melhor, eu vejo e ouço todos os discentes [...] então eu consigo ter uma percepção mais direta de cada aluno, consigo fazer anotações mais pontuais.

Afetados pela obrigatoriedade de efetuar mudanças, observamos oportunidades concretas de um repensar do sistema escolar quanto ao processo de ensino-aprendizagem certamente incidindo no ensino presencial, como a educadora Samara ressalta: Não dá para pegarmos esse conhecimento (construído no trabalho remoto) absorver ele e quando voltar para o sistema presencial, simplesmente deixar ele de lado, deixar ele para trás, vamos ter que agregá-lo a nossa prática pedagógica.

Além disso, Thomas aponta para o ensino remoto como algo que abre novos caminhos ao afirmar que também pode ser libertador e ter nos familiares o apoio eficaz diante das dificuldades. Elaine enfatiza: Na escola do meu filho eles tem se preocupado com o tempo de aula na internet, de atividades, não tem sido fácil, mas tenho me aproximado mais desse universo. E Riana destaca: Os familiares confiam, conhecem meu trabalho e eu tenho liberdade para dialogar com eles.

Esses destaques, mesmo em meio ao caos do novo, também revelam uma aproximação das famílias junto ao sistema escolar a partir de um estreitamento das relações entre estudantes, docentes e familiares, o que requer novos olhares sobre os diferentes processos de aprendizagem.

Os afetos implicados nesse processo - No cerne dos impactos causados pela pandemia, em meio ao isolamento social, a evidência de que o novo nos coloca em situações conflitantes e provoca diferentes reações que instauram movimentos ou não, trouxe à tona uma diversidade de sentimentos vivenciados pelos estudantes, pelos docentes e por suas famílias, tanto internamente quanto na inter-relação entre os três contextos.

Deparamo-nos com diversos sentimentos, como expressam as falas dos diferentes atores. Os estudantes Ane e Thomas tratam da falta do contato com docentes e/ou colegas, e do quanto 
é ruim não poder sair de casa, e de ter que limitar-se às atividades do cotidiano de uma casa. Destacamos uma fala muito significativa de um dos estudantes que revela sua dor:

Eu me sinto (pausa) um pouco solitário[ ... . tem momentos bons[_...] mas tem momentos bem dificeis [...] o contato remoto não me agrada porque não me tira a saudade [...] muita gente sofrendo [ $\ldots]$ Ver essas coisas assim é triste, sinto muita falta. (Thomas).

De outro lado, Ane nos diz: tem dia que a gente se sente esgotada porque está muito cansativo ficar em casa o tempo todo, sem poder sair.

A adolescência é um momento de grande interação com seus pares, fase na qual é importante vivenciar outras experiências em outros espaços. Não é suficiente interagir pelas redes sociais, o contato físico (do aperto de mão, do abraço, das risadas, das conversas, do olhar cara a cara) traz um diferencial que não acontece de forma on-line; os diferentes espaços permitem um deslocamento importante para confrontar os diferentes territórios, o que fica limitado no contexto on-line.

Por outro lado, as educadoras e as mães também expressam suas dificuldades frente às muitas demandas desse novo modelo de ensino, o remoto: Tudo é realmente muito difícil, estressante, é muito cansativo [...] foi muito difícil para mim esse período, foi muito estressante, sobretudo quanto às tarefas domésticas (Samara, educadora); o mais difícil foi conciliar as três jornadas [...] sem sair de casa (Elaine, mãe). Há dificuldades de articular as diferentes tarefas e criar diferentes espaços para viver as diferentes faces dos fazeres (pessoais, profissionais e domésticos).

Contudo, a experiência do isolamento pode tornar-se um momento de reflexão e avaliação de suas vidas, como ilustra a fala da estudante Ane: Possibilitar um momento muito bom para descobrir realmente quem a gente é, o que a gente gosta de fazer, as coisas que a gente prefere fazer; referindo-se a curtir mais a vida ao sair com os amigos, ir ao parque, participar das festas, pois ao longo da sua entrevista ela revelou que antes da pandemia ela se isolava muito. Por outro lado, uma das mães, Elaine, afirma: É uma situação atípica [...] a gente tem que fazer o nosso melhor, aproveitar o tempo melhor, cuidar da saúde, do emocional.

Nessas falas, o descobrir-se e procurar cuidar do emocional explicita que no confronto com esses diferentes sentimentos há a oportunidade de avaliar-se a si próprio e buscar aprofundar as análises para o campo do subjetivo, área em que culturalmente nossa sociedade não tem investido na proporção necessária. Avaliar-se a si próprio é um autoconfronto, que é atravessado por sofrimento, e ao mesmo tempo envolto por prazer. Esse movimento permite a tomada de consciência, que mobiliza na perspectiva de um movimento de reaprendizagem. 


\section{Considerações finais}

O objetivo do presente artigo foi observar e discutir como ocorrem as relações de ensinoaprendizagem no ensino remoto no âmbito dos docentes, dos discentes e das famílias, entre sistema familiar e sistema escolar, focando principalmente as vivências e aprendizagens dos discentes para propor reflexões para um possível cenário pós-pandemia.

No cotidiano do isolamento, adaptar-se às novas rotinas se revela estressante e até desalentador. Contudo, da paralisação veio a (re)ação que transformou esse momento em reflexão para mudanças futuras, além de mudanças no cotidiano, por meio de atividades físicas, cuidados com o lar (casa, culinária), nas relações familiares, por meio de atividades envolvendo a todos. O contexto escolar passou por profundas mudanças, com momentos sofridos e complexos, até alcançar uma nova maneira de se pensar o processo de ensino-aprendizagem para o contexto remoto.

Essas reflexões envolveram momentos pessoais, quando observamos as diferentes pessoas em busca de repensar sua vida; familiares, sentindo a necessidade de ressignificar a vivência mais próxima para uma convivência mais saudável; e nas escolas, para minimizar a distância física por meio da tecnologia. Diante disso, constatamos o quanto estas relações intersubjetivas entre sistema escolar e sistema familiar se transformaram positivamente, apesar das grandes dificuldades e adversidades do contexto. Afinal, a relação estabelecida com nós mesmos e com os outros provoca um agir diante das problematizações.

Se internamente a pandemia acarretou o isolamento social, gerou estresse e/ou conflitos, isso parece ter uma relação profunda com a necessidade de mudanças quanto às rotinas de cada um. Especificamente no caso das relações de ensino-aprendizagem, os entrevistados revelam que se tornou um processo muito intenso e carregado, uma vez que as mudanças exigiram esforços redobrados da instituição escolar e também da instituição familiar.

À escola coube a responsabilidade de reinventar o ensino, e os familiares se viram diante da necessidade de transformar o lar, acrescendo espaços para o trabalho dos familiares e os estudos dos filhos. Isso exigiu a necessidade de oportunizar o acesso tecnológico para todos, a mediação dos familiares na relação estudantes (filhos) e docentes. Essa reorganização envolveu desgastes relativos ao repensar os tempos, as atenções, desembolsar dinheiro para ter uma estrutura mínima em casa, tendo consciência de que uma grande parte das escolas e famílias não conseguiu realizar todas essas adequações, resultando na sua exclusão deste universo de ensino-aprendizagem.

Diante do exposto, os resultados sinalizam para o quanto a pandemia desnudou e aprofundou as desigualdades sociais, além de colocar em evidência uma diversidade de afetos, dificuldades de organização das rotinas, de busca de estratégias de estudos e de articulação das diferentes funções. De outro lado, esse tempo de pandemia possibilitou repensar o tempo familiar, 
refletir quanto aos papéis e as devidas responsabilidades no cotidiano do lar; e quanto à educação escolar, coube buscar novas estratégias de estudos, repensar a construção da autonomia nesse processo de ensino-aprendizagem, conhecer a si mesmo, repensar os afetos e valorizar as relações sociais. Costuma-se dizer que 'do caos emerge luz'. Nesse sentido, em meio às problematizações e/ou conflitos advindos da pandemia, vivenciamos um processo de desconstrução para instaurar o novo, envolto em muitas dúvidas, incertezas e desconhecimento.

Em um cenário pós-pandêmico certamente se apresentam variados desafios para o sistema familiar e escolar. No referente ao sistema familiar, cabe buscar alternativas de convivência que repensem os afetos, os papéis e/ou responsabilidades de forma democrática, minimizando a interferência do pessoal no profissional e num clima de leveza para todos. Além disso, o desafio de elucidar o papel da família no contexto escolar, com o objetivo de dar apoio para viabilizar tempo/espaço adequado de estudo, assim dando continuidade às orientações escolares, confiando no papel da escola e na sua responsabilidade no processo de ensino-aprendizagem.

Quanto ao sistema escolar, destaca-se o ganho nos estudos possibilitando o trabalho remoto com a inclusão dos recursos tecnológicos de forma didática, aliado ao desafio de buscar soluções para oferecer as devidas condições de acesso tecnológico às classes populares, e a possibilidade com vistas a um ensino mais moderno, atual e adequado às condições da sociedade. Outro aspecto, a partir da fala dos estudantes, aponta para a busca de alternativas mais efetivas para a construção da autonomia com a devida orientação para as possibilidades dos recursos tecnológicos, o que pode ser agregado como novos caminhos no processo de ensinoaprendizagem que insira a todos.

Fica, pois, o desafio de introduzir essas novas possibilidades sem excluir o que já vem acontecendo. Cabe continuar a investigar diferentes formas de ação e/ou políticas públicas eficazes para que o isolamento social diminua seus efeitos negativos sobre a saúde mental, o bemestar social, a condição financeira das pessoas, e se assegure o devido acesso ao ensino remoto com qualidade e para todos, o que continua sendo um grande desafio a enfrentar e vencer.

\section{Referências}

AGUIAR, Wanda M. J.; OZELLA, Sergio. Núcleos de significação como instrumento para a apreensão da constituição de sentidos. Psicologia, Ciência e Profissão, v. 26, n. 2, p. 22245, 2006. Disponível em: https://www.scielo.br/j/pcp/a/QtcRbxZmsy7mDrqtSjKTYHp/?lang=pt\&format=pdf. DOI: https://doi.org/10.1590/s 1414-98932006000200006.

ALVES, Marly G. S. Vivências lúdicas na educação infantil e o contexto de pandemia de Covid-19 no Brasil. 62 f. 2020. TCC em Educação pela UFPB - CE, Julho, 2020. Disponível em: https://repositorio.ufpb.br/jspui/handle/123456789/17887. 
BAHIA, Norinês P. Pandemia!!! E agora? Reflexões sobre o cotidiano escolar a distância. Cadernos CERU, série 2, v. 31, n. 1, jun. 2020, 116-125. Disponível em: https://www.revistas.usp.br/ceru/article/view/174489/163253. DOI: https://doi.org/10.11606/issn.2595-2536.v31i1p116-125.

CIPRIANO, Jonathan A.; ALMEIDA, Leila C. C. S. Educação em tempos de pandemia: análises e implicações na saúde mental do professor e aluno. CONEDU - VI Congresso Nacional de Educação, 15-17 de outubro de 2020 - Maceió, AL.

GEERTZ, Clifford. A interpretação das culturas. 13. reimp. Rio de Janeiro: LTC, 2008.

HONORATO, Hercules G.; MARCELINO, Aracy C. K. B. A arte de ensinar e a pandemia COVID-19: a visão dos professores. REDE: Revista Diálogos em Educação, v. 1, n. 1, janeirojunho 2020. DOI: https://doi.org/10.29327/218479.1.1.

KOHAN, Walter. Sobre o saber e o não saber de um professor. Revista do GEEMPA: 45 anos de pesquisa, formação e ação, n. 11, p. 47-52, Porto Alegre: Geempa, setembro de 2015.

KOHAN, Walter. Matilde e a infância de todos nós. In: WALLENSTEIN, Madalena (Coord.). Nós pensamos todos em nós. Edição Fundação Centro Cultural de Belém, maio 2016. p. 192-199.

MARTINS, Vivian; ALMEIDA, Joelma. Educação em tempos de pandemia no Brasil: saberes fazeres escolares em exposição nas redes e a educação on-line como perspectiva. 2020. REDOC - Revista Docência e Cibercultura, Rio de Janeiro, v. 4, n. 215-224, maio/ago. 2020. DOI: https://doi.org/10.12957/redoc.2020.51026.

PEREIRA, Mara D. et al. A pandemia de COVID-19, o isolamento social, consequências na saúde mental e estratégias de enfrentamento: uma revisão integrativa. Research, Society and Development, v. 9, n. 7, 2020. DOI: https://dx.doi.org/10.33448/rsd-v9i7.4548.

SANTOS, Geny; MENDONÇA, Marilane. Pandemia e o ensino remoto: uma reflexão acerca da vivência afetivo-emocional dos estudantes. Revista Educação e Humanidades, v. II, n. 1, jan-jun, 2021 , p.110-131. Disponível em:

https://www.periodicos.ufam.edu.br/index.php/reh/article/view/8499/6054.

SENTINELI, Tiago A.; INSFRAN, Fernanda. Familiares, docentes e escolas na pandemia: do contato à relação. In: INSFRAN, Fernanda F. N. et al. (Orgs.). Fraturas expostas pela pandemia: escritos e experiências em educação. Campos dos Goytacazes, RJ: Encontrografia, 2020, p.118136. Disponível em: http://encontrografia.com/wp-content/uploads/2020/10/ebookFraturas-expostas-pela-pandemia.pdf.

TUBOITI, Nair C. S. "Ninguém nasce alfabetizadora, aprende-se a ser": processo de aprendizagem de alfabetizadoras em proposta pós-construtivista. 295 f. nov/2018. Tese (Doutorado em Psicologia) - Universidade Católica de Brasília, Brasília, DF. 2018. Disponível em: https://docplayer.com.br/196776248-Pro-reitoria-academica-escola-de-saude-e-medicinaprograma-de-pos-graduacao-stricto-sensu-em-psicologia.html. 